\title{
Chemical neurolysis of the inferior hypogastric plexus for the treatment of cancer-related pelvic and perineal pain
}

\author{
Sahar Abd-Elbaky Mohamed PhD, Doaa Gomaa Ahmed PhD, Mohamad Farouk Mohamad PhD
}

SA Mohamed, DG Ahmed, MF Mohamad. Chemical neurolysis of the inferior hypogastric plexus for the treatment of cancer-related pelvic and perineal pain. Pain Res Manag 2013;18(5):249-252.

BACKGROUND: Various interventions, including the superior hypogastric plexus block and ganglion impar block, are commonly used for the treatment of pelvic or perineal pain caused by cancer. The inferior hypogastric plexus block (performed using a trans-sacral approach under fluoroscopy and using a local anesthetics/steroid combination) for the diagnosis and treatment of chronic pain conditions involving the lower pelvic viscera was first described in 2007. Neurolysis of the inferior hypogastric plexus may be useful for the treatment of pelvic and perineal pain caused by cancer.

OBJECTIVES: To assess the feasibility, safety and efficacy of the newly introduced inferior hypogastric plexus block, performed using a trans-sacral approach, for the relief of cancer-related pelvic and perineal pain.

METHODS: A total of 20 patients with cancer pain in the pelvis and/or perineum were injected with $6 \mathrm{~mL}$ to $8 \mathrm{~mL}$ of $10 \%$ phenol bilaterally by passing a spinal needle through the sacral foramen to perform the inferior hypogastric block. Pain intensity (measured using a visual analogue scale), sleep score, activity score, psychological score and oral morphine consumption pre- and postprocedure were measured.

RESULTS: Two of the 20 patients died during the follow-up period and were, therefore, excluded from the study. All patients presented with cancer-related pelvic, perineal or pelviperineal pain. Pain scores were reduced from a mean $( \pm \mathrm{SD})$ of $7.22 \pm 1.31$ preprocedurally to $4.06 \pm 1.73$ one week postprocedurally $(\mathrm{P}<0.05)$. In addition, the mean consumption of morphine (delivered via $30 \mathrm{mg}$ sustained-release morphine tablets) was reduced from $106.67 \pm 32.90 \mathrm{mg}$ to $61.67 \pm 40.48 \mathrm{mg}$ after one week $(\mathrm{P}<0.05)$. No complications or serious side effects were encountered during or after the block.

DISCUSSION AND CONCLUSION: The approach provides a good alternative technique for the treatment of low pelvic and perineal cancerrelated pain. Additional studies are required for evaluation and refinement of the technique using other radiological techniques.

Key Words: Cancer pain; Inferior hypogastric plexus block; Neurolysis; Pelvic pain; Perineal pain; Superior hypogastric plexus block

$\mathrm{T}$ he inferior hypogastric plexus is the primary autonomic neural coordinating centre in the pelvis. It integrates both parasympathetic and sympathetic output and receives input from the sacral level of the spinal cord $(1,2)$. The inferior hypogastric plexuses are formed by efferent sympathetic fibres from the hypogastric nerves and from pelvic splanchnic nerves, preganglionic parasympathetic fibres from pelvic splanchnic nerves and visceral afferent fibres from pelvic viscera (3).

Despite recent refinements in the technique for performing superior hypogastric plexus blocks, the lower pelvic organs and genitalia are innervated by nerve fibres from the presacral inferior hypogastric plexus, and these fibres are not readily blocked using paravertebral or transdiscal approaches (4).

The inferior hypogastric plexus block was first described by Schultz (4) for the diagnosis and treatment of chronic pain conditions involving

\section{La neurolyse chimique du plexus hypogastrique inférieur pour le traitement de la douleur pelvienne et périnéale liée au cancer}

HISTORIQUE : Diverses interventions, y compris le bloc du plexus hypogastrique supérieur et le bloc du ganglion impar, sont couramment utilisées pour traiter la douleur pelvienne ou périnéale causée par le cancer. Le bloc du plexus hypogastrique inférieur (effectué au moyen d'une approche trans-sacrée sous fluoroscopie et d'une association d'anesthésie locale et de stéroïdes) pour diagnostiquer et traiter les douleurs chroniques des viscères pelviennes inférieures a été décrit pour la première fois en 2007. La neurolyse du plexus hypogastrique inférieur peut être utile pour traiter la douleur pelvienne et périnéale causée par le cancer.

OBJECTIFS : Évaluer la faisabilité, la sécurité et l'efficacité du nouveau bloc du plexus hypogastrique inférieur, effectué au moyen d'une approche trans-sacrée, pour soulager la douleur pelvienne et périnéale liée au cancer. MÉTHODOLOGIE : Au total, 20 patients ayant des douleurs cancéreuses du bassin ou du périnée ont reçu une injection bilatérale de $6 \mathrm{~mL}$ à $8 \mathrm{~mL}$ de phénol $10 \%$ au moyen d'une aiguille spinale insérée par le trou vertébral pour effectuer le bloc hypogastrique inférieur. Les chercheurs ont mesuré l'intensité de la douleur (mesurée au moyen d'une échelle analogique visuelle), l'indice de sommeil, l'indice d'activité, l'indice psychologique et la consommation de morphine par voie orale avant et après l'intervention.

RÉSULTATS : Deux des 20 patients sont décédés pendant la période de suivi et ont donc été exclus de l'étude. Tous les patients présentaient des douleurs pelviennes, périnéales ou pelvi-périnéales liées au cancer. Les indices de douleur ont fléchi d'une moyenne $( \pm E ́ T)$ de $7,22 \pm 1,31$ avant l'intervention à 4,06 $\pm 1,73$ une semaine après l'intervention $(\mathrm{P}<0,05)$. De plus, la consommation moyenne de morphine (administrée sous forme de comprimés de morphine de $30 \mathrm{mg}$ à libération soutenue) a décru de $106,67 \pm 32,90 \mathrm{mg}$ à $63,33 \pm 43,52 \mathrm{mg}$ au bout d'une semaine $(\mathrm{P}<0,05)$. Aucune complication ou effet secondaire grave ne s'est manifesté pendant ou après le bloc.

EXPOSÉ ET CONCLUSION : Cette approche est une bonne technique de rechange pour traiter les douleurs périnéales et pelviennes basses liées au cancer. D'autres études s'imposent pour évaluer et raffiner la technique au moyen d'autres techniques radiologiques.

the lower pelvic viscera. It involves using a combination of local anesthetics/steroid and a trans-sacral approach under fluoroscopy.

The purpose of the present study was to assess the feasibility, safety and efficacy of a newly introduced neurolytic inferior hypogastric block using phenol administered through the trans-sacral approach for the relief of cancer-related pelvic and perineal pain.

\section{METHOD}

After obtaining approval from the hospital ethics committee and written informed consent from the participants, evaluation of inferior hypogastric plexus block was undertaken for 20 patients who had cancer-related pelvic pain, perineal pain, or both pelvic and perineal pain at the South Egypt Cancer Institute (Assiut, Egypt).

Inclusion criteria: Patients with sympathetically-maintained cancer pain arising from the bladder, prostate, penis, vagina, rectum, anus,

South Egypt Cancer Institute, Anesthesia, Intensive care and Pain Management, South Egypt Cancer Institute, Assiut, Egypt

Correspondence: Dr Doaa Gomaa Ahmed, Anesthesia, Intensive Care and Pain Management, South Egypt Cancer Institute, Almethaque Street,

Manshiet Elomra, PO Box 71516, Assiut, Egypt. Telephone 20-111-360-7950, fax 002-088-234-3268, e-mail doaagomaa78@yahoo.com 


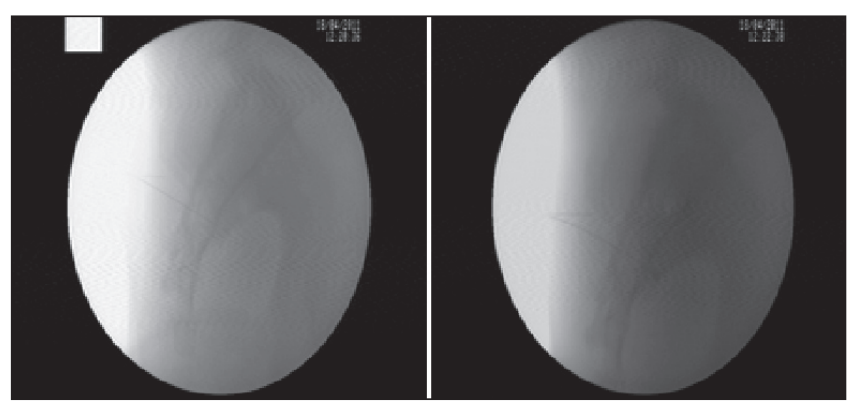

Figure 1) Advancement of the needle through the dorsal sacral foramen toward the medial interior edge of the ventral sacral foramen

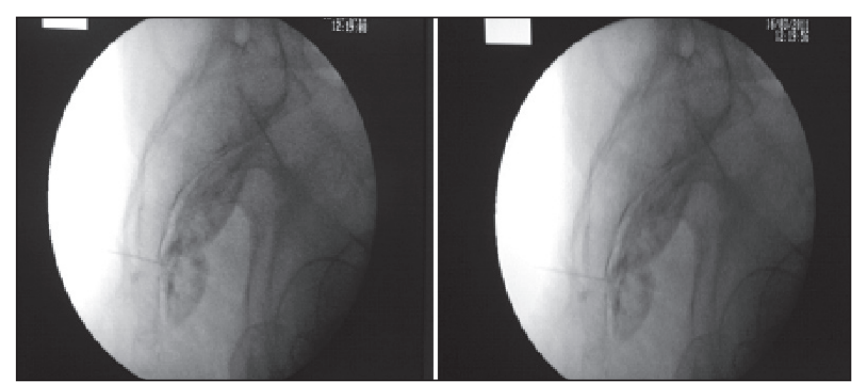

Figure 2) The successful spread of the dye and phenol after bilateral transsacral injection

perineum or any other pelvic organ; patients with pain no longer controlled with $30 \mathrm{mg}$ oral morphine sustained-release tablets (MST) and $25 \mathrm{mg}$ amitriptyline tablets, or patients experiencing excessive sedation or other side effects that they deemed unacceptable despite adequate pain control.

Exclusion criteria: Patients with coagulopathies or allergies to the contrast dye or phenol; patients receiving radiation or chemotherapy within four weeks of the neurolytic block; and patients with moderate or major cardiac/respiratory disease or hepatic or renal dysfunction were excluded from the present study.

All patients underwent diagnostic blocks using local anesthesia one week before the neurolytic blockade was performed and had successful diagnostic test results (defined as a $50 \%$ reduction in pain scores measured using a visual analogue scale [VAS] within $24 \mathrm{~h}$ ). Patients without successful diagnostic test results were excluded.

All patients were admitted to the hospital ward. An 18-gauge intravenous catheter was fixed, and patients received $1 \mathrm{~L}$ lactated Ringer's solution preprocedurally. All patients were then transported to the $\mathrm{x}$-ray room and received conscious sedation using $0.1 \mathrm{mg} / \mathrm{kg}$ midazolam and $1 \mu \mathrm{g} / \mathrm{kg}$ fentanyl. Standard monitoring recommended by the American Society of Anesthesiologists were used, including electrocardiography, blood pressure and pulse oximetry measurements.

\section{Procedure}

The patient was placed prone on the $\mathrm{x}$-ray table. An anterior-posterior scout view of the sacrum was obtained and the C-arm was tilted cephalad to view the sacral foramina 'end-on' as circles or semicircles on each side of the midline. Using fluoroscopy, an entrance point was marked on the skin surface $1 \mathrm{~cm}$ to $2 \mathrm{~cm}$ lateral to the lateral edge of the S2 or S3 sacral foramen on the side to be blocked. The foramen that was most easily visible was usually chosen. This block may be performed through S1, S2, S3 or S4, although S2 is usually the preferred access level. After the skin was cleaned, a skin wheal was raised over the entrance site and a path of anesthesia toward the targeted sacral foramen was infiltrated. An appropriately bent 3.5 inch, 25 -gauge spinal needle was passed through the anesthetized track and advanced to the lateral aspect of the dorsal sacral foramen until contact with bone was made. The needle was advanced slowly and incrementally under fluoroscopic guidance through the dorsal sacral foramen toward the medial interior edge of the ventral sacral foramen, until contact was made with the medial bony edge of the ventral sacral foramen. When sacral paresthesia was encountered, the needle was retracted and rotated slightly to move past the sacral nerve root. A small, incremental dose of $1 \%$ lidocaine $(0.1 \mathrm{~mL}$ to $0.3 \mathrm{~mL})$ during needle advancement improved patient comfort without creating blockade of sacral nerve roots. The needle was manoeuvred along the medial edge of the ventral sacral foramen to exit the ventral foramen as medially as possible. The needle was advanced anteromedially an additional $1 \mathrm{~mm}$ toward the midline presacral plane and the contrast medium was injected under live continuous fluoroscopy to ensure negative vascular uptake. If the needle was in the optimal position, the contrast would spread cephalad and caudad along the presacral plane conforming to the midline, ventral surface of the sacrum.

When proper needle tip position was assured, $6 \mathrm{~mL}$ to $8 \mathrm{~mL}$ of $10 \%$ phenol in saline was injected in each side. If injected contrast and medication spread across the midline from the side of needle placement, then a unilateral block could be sufficient. More commonly, however, contrast spread is primarily unilateral, necessitating a bilateral needle placement to complete blockade of the right and left inferior hypogastric plexuses (Figure 1, Figure 2).

Following the block, the patients were taken to the postanesthetic care unit for the following $24 \mathrm{~h}$.

\section{Parameters assessed}

Pain intensity was measured using a $10 \mathrm{~cm}$ VAS, ranging from 0 ('no pain') to 10 ('worst imaginable pain'). VAS scores were measured before the procedure and at $30 \mathrm{~min}, 60 \mathrm{~min}, 2 \mathrm{~h}, 6 \mathrm{~h}, 24 \mathrm{~h}$, one week, two weeks, four weeks and two months after the procedure. A failed block was defined as failure to lower VAS scores by $50 \%$ of the preprocedural VAS score. Total MST consumption was recorded preprocedurally, at the first $24 \mathrm{~h}$ postprocedurally in the postanesthetic care unit and at follow-up visits. The time required to perform the block, any complications during or after the procedure (including transient paresthesia, rectal puncture, vascular penetration of one of the pelvic vessels, hematoma, infection, dural puncture, bowel/bladder dysfunction, pain on injection, hypotension from the sympathetic block or any other complication) and hemodynamic parameters (blood pressure, heart rate, oxygen saturation) before, during and after the procedure for $24 \mathrm{~h}$ at the postanesthetic care unit were also examined. The patients were discharged after $24 \mathrm{~h}$ and were followed-up for two months, at weeks 1,2 and 4, and at two months.

\section{Statistical analysis}

Statistical analysis was performed using SPSS version 16 (IBM Corporation, USA). Values are presented as mean $\pm \mathrm{SD}$, range, percentage and number. Statistical analysis was performed using Wilcoxon signed ranks test to assess the change in VAS scores and morphine consumption from baseline. Differences were considered to be statistically significant at $\mathrm{P}<0.05$.

\section{RESULTS}

A total of 20 patients were enrolled in the present study and underwent inferior hypogastric plexus block. Two patients died during the follow-up period and were excluded from the analysis. Demographic data, clinical data and the mean duration of the procedure are presented in Table 1.

The mean $( \pm \mathrm{SD})$ VAS score of the patients was $7.22 \pm 1.31$ before the block was performed. VAS scores decreased significantly $(\mathrm{P}<0.05)$ immediately after injection compared with the preprocedural period and was sustained during all follow-up assessments (Table 2, Figure 3), with maximum reduction (by $43.8 \%$ of the baseline VAS score $[\mathrm{P}<0.05])$ observed after one week.

All patients were either receiving high doses of MST with inadequate pain control or were limiting their morphine intake despite significant pain relief because of its side effects (sedation, nausea, vomiting and constipation). Mean consumption of MST before the block was $106.67 \pm 32.90 \mathrm{mg} /$ day, and was significantly reduced at $24 \mathrm{~h}$, one week, two weeks and four weeks after the block $(\mathrm{P}<0.05)$, but was not significantly reduced after two months, with maximum 
TABLE 1

Patient characteristics, clinical data and mean duration of procedure

\begin{tabular}{lc}
\hline Characteristic & \\
\hline Age, years & $52.5 \pm 10.7$ \\
Sex, male/female, $\mathrm{n} / \mathrm{n}$ & $11 / 7$ \\
Body weight, $\mathrm{kg}$ & $67.4 \pm 13.1$ \\
Height, $\mathrm{cm}$ & $161.5 \pm 6.9$ \\
Cancer diagnosis, $\mathrm{n}$ & \\
$\quad$ Bladder & 8 \\
Cervix & 1 \\
Ovary & 3 \\
Prostate & 1 \\
Rectum & 4 \\
Vulva & 1 \\
Site of pain, $\mathrm{n}$ & \\
Pelviperineal & 8 \\
Perineal & 6 \\
Pelvic & 4 \\
Duration of the procedure, min & $38.3 \pm 6.6$
\end{tabular}

Data presented as mean $\pm S D$, unless otherwise indicated

TABLE 2

Pain intensity, measured using a visual analogue scale (VAS)

\begin{tabular}{lc}
\hline Time of administration of VAS & Score \\
\hline Baseline & $7.22 \pm 1.31$ \\
$30 \mathrm{~min}$ & $6.61 \pm 1.42^{*}$ \\
$1 \mathrm{~h}$ & $5.67 \pm 1.33^{*}$ \\
$2 \mathrm{~h}$ & $5.50 \pm 1.34^{*}$ \\
$6 \mathrm{~h}$ & $4.89 \pm 1.37^{*}$ \\
$24 \mathrm{~h}$ & $4.28 \pm 1.78^{*}$ \\
One week & $4.06 \pm 1.73^{*}$ \\
Two weeks & $4.28 \pm 1.84^{*}$ \\
Four weeks & $4.50 \pm 1.89^{*}$ \\
Two months & $5.11 \pm 1.78^{*}$ \\
\hline
\end{tabular}

Data presented as mean $\pm S D$. ${ }^{*} P<0.05$ versus preprocedural value

reduction (by $40.3 \%$ of the baseline MST consumption) observed after one week (Table 3).

Successful pain relief (VAS score below $50 \%$ of the preprocedural measured VAS score) occurred in eight patients (44.4\%) based on immediate pain relief and no evidence of complications. One-half of the patients had experienced perineal pain, and the other one-half had experienced either pelvic pain or pelviperineal pain.

No significant changes were observed in hemodynamic variables (blood pressure, heart rate and oxygen saturation) measured during the first $24 \mathrm{~h}$ after the procedure. Complications encountered during the procedure are listed in Table 4.

\section{DISCUSSION}

The bilateral inferior hypogastric plexuses are interconnected networks of nerves lying within the presacral tissues, which lie along the anterior surface of the sacrum medial to the foramina sacralia on either side of the rectum, ventral to the S2, S3, and S4 spinal segments $(3,5)$.

Schultz (4) was the first to describe the inferior hypogastric plexus block through the trans-sacral approach under fluoroscopy, using a local anesthetic/steroid combination, for the diagnosis and treatment of chronic pain conditions involving the lower pelvic viscera. The present study is the first to report the use of phenol for neurolysis of the inferior hypogastric plexus in the treatment of cancer-related pelvic and perineal pain.

Visceral pelvic pain occurs in association with oncological disease $(6,7)$, particularly bladder cancer, which is the most common malignancy

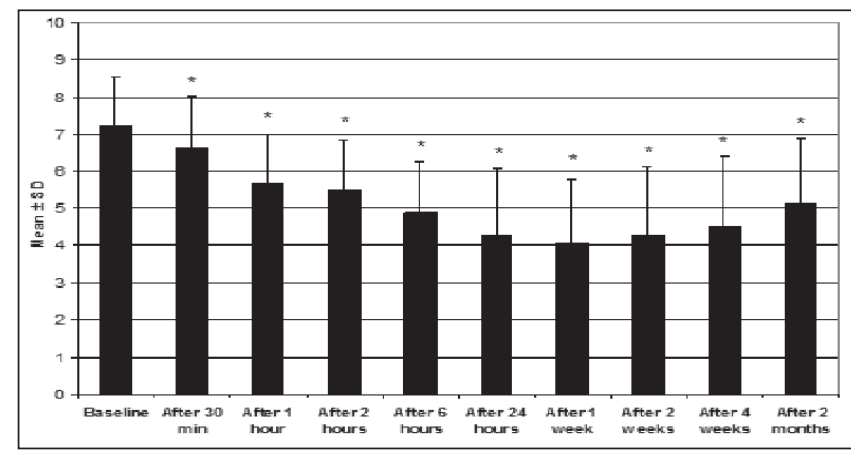

Figure 3) Mean pain intensity score, measured using a visual analogue scale $(\mathrm{cm})$; columns represent mean $\pm S D . * P<0.05$ versus preprocedural value

TABLE 3

Morphine consumption

\begin{tabular}{lc}
\hline Time & Morphine consumption, mg/day \\
\hline Baseline & $106.67 \pm 32.90$ \\
$24 \mathrm{~h}$ & $85.00 \pm 37.46^{\star}$ \\
One week & $61.67 \pm 40.48^{\star}$ \\
Two weeks & $63.33 \pm 43.52^{\star}$ \\
Four weeks & $71.67 \pm 50.56^{\star}$ \\
Two months & $85.00 \pm 48.54$ \\
\hline
\end{tabular}

Data presented as mean $\pm S D$. ${ }^{*} P<0.05$ versus preprocedural value

\section{TABLE 4}

Frequency of adverse effects

\begin{tabular}{ll}
\hline Variable & $\mathbf{n}(\%)$ \\
\hline Transient paresthesia & $7(38.8)$ \\
Pain on injection & $4(22.2)$ \\
Vascular penetration & $1(5.5)$ \\
Hematoma & $0(0)$ \\
Infection & $0(0)$ \\
Dural puncture & $0(0)$ \\
Bowel/bladder dysfunction & $0(0)$ \\
Rectal puncture & $0(0)$ \\
Hypotension & $0(0)$ \\
\hline
\end{tabular}

among Egyptian men. This has previously been attributed to Schistosoma infection (8). Approximately $25 \%$ of patients have an inoperable tumour on presentation (9). This served as motivation for our group to examine the efficacy of the newly described sympathetic axis block using phenol.

Schultz reported a success rate of $73 \%$ when performing 15 blocks on 11 patients who suffered from chronic pelvic pain, with mean $( \pm$ SD) VAS scores of $7.4 \pm 2.3$ and $5.0 \pm 2.7$ pre- and postprocedure, respectively. We observed a lower success rate $(44.4 \%)$, with VAS scores reduced from $7.22 \pm 1.31$ preprocedurally to $4.06 \pm 1.73$ postprocedurally. This difference in success rate can be attributed to the density of the surrounding connective tissue (10) and the possible involvement of structures other than visceral by the malignancy (11), which may limit the spread of the phenol.

Transient paresthesia was the most common adverse event encountered during trans-sacral blockade of the inferior hypogastric plexus, occurring in $38.8 \%$ of the procedures performed. This occurs mainly because the sacral spinal nerves, with their dorsal and ventral rami, course close to the advancing needle and may be occasionally contacted by the needle tip (4). Transient paresthesia can be minimized with slow and careful advancement of the needle using frequent injections of small volumes of diluted local anesthetic as the needle advances. If paresthesia begins to occur, one can direct the path of the needle around the path of the traversing nerve before advancing further by rotating the bent needle tip slightly, as described in the original report of the technique. 
Performing the block on patients with pelvic, perineal or pelviperineal cancer-related pain resulted in better pain relief in patients with low pelvic and perineal pain compared with individuals with isolated pelvic pain.

Other neurolytic techniques commonly used for pelvic and perineal pain include the superior hypogastric plexus block (12-16) and the ganglion impar block (17-20).

Cancer patients presenting with low pelvic pain combined with perineal pain (anal pain or pain arising from the genitalia) may benefit from inferior hypogastric plexus block rather than superior hypogastric plexus block and ganglion impar block, especially because this area is innervated by nerve fibres from the presacral inferior hypogastric plexus that will not be blocked by the superior hypogastric plexus block, even with the refinement of its techniques to include either paravertebral or transdiscal approaches (4).

Whenever pain is amenable to be treated by an inferior hypogastric plexus block, it is safer to perform this procedure than the superior hypogastric plexus block because it eliminates the risk of injuring the structures overlying the superior hypogastric plexus such as the bowel, bladder or common iliac artery.

The anterior approach to the superior hypogastric plexus block carries a risk of infection when passing through the bowel; furthermore, the transdiscal approach is associated with a potential risk of discitis, disk rupture or disk herniation, and requires preparation with antibiotics.

\section{REFERENCES}

1. Christo J, Hobelmann G. Pelvic Pain. In: Smith HS, ed. Current Therapy in Pain, 1st edn. Philadelphia: Saunders-Elsevier, 2009:216-27

2. Waldman S. Hypogastric Plexus Block. In: Waldman SD. Pain review, 1st edn. Philadelphia: Saunders-Elsevier. 2009:538-41.

3. Waldman S. Atlas of Interventional Pain Management, 2nd edn. Philadelphia: Saunders, 2004.

4. Schultz D. Inferior hypogastric plexus blockade: A transsacral approach. Pain Physician 2007;10:757-63.

5. Michael H. Basic Neuroanatomy and neurophysiology of urethrovesical function with special reference to extended hysterectomy. CME J Gynecol Oncol 2002;7:32-5.

6. Ischia S, Luzzani A, Ischia A, Magon F, Toscano D. Subarachnoid neurolytic block [L5-S1] and unilateral percutaneous cervical cordotomy in the treatment of pain secondary to pelvic malignant disease. Pain 1984;2:139-49

7. Wang JK. Intrathecal morphine for intractable pain secondary to cancer of pelvic organs. Pain 1985;21:99-102.

8. Fedewa SA, Soliman AS, Ismail K, et al. Incidence analyses of bladder cancer in the Nile delta region of Egypt. Cancer Epidemiol 2009;33:176-81.

9. Khaled HM. Systemic management of bladder cancer in Egypt: Revisited. J Egypt Natl Canc Inst 2005;17:127-31.

10. Alsaid B, Bessede T, Karam I, et al. Coexistence of adrenergic and cholinergic nerves in the inferior hypogastric plexus: Anatomical and immunohistochemical study with 3D reconstruction in human male fetus. J Anat 2009;214:645-54.

11. Mercadante S, Fulfaro F, Casuccio A. Pain mechanisms involved and outcome in advanced cancer patients with possible indications
Regarding the risk of rectal injury during the block procedure, in the case of the inferior hypogastric plexus block, this may occur if the needle is advanced too deeply into the presacral tissue, and it can be easily avoided by careful visualization of the needle depth using the lateral fluoroscopy because the rectum is separated from the ventral surface of the sacrum by $>1 \mathrm{~mm}$ (4). However, in the case of ganglion impar block involving the conventional transanococcygeal membrane technique, there is a need for continuous rectal examination by the operator with the index finger to prevent rectal perforation (20).

Inferior hypogastric plexus block is a good alternative technique for the treatment of cancer-related pelvic, perineal or pelviperineal pain, with better results in patients with prominent lower pelvic and perineal pain. Better success rates may be achieved if the technique is re-evaluated in selected patients with low pelvic or perineal pain, and if other radiological techniques, such as ultrasonography or computed tomography, are incorporated.

\section{CONCLUSION}

The inferior hypogastric plexus block is a good alternative neurolytic technique for the treatment of low pelvic and perineal pain. However, large, well-controlled studies and refinement of the technique using other radiological methods are needed to improve the safety and efficacy of this new neurolytic technique.

for celiac plexus block and superior hypogastric plexus block. Tumori 2002;88:243-5.

12. Plancarte R, Amescua C, Patt RB, Aldrete JA. Superior hypogastric plexus block for pelvic cancer pain. Anesthesiology 1990;73:236-9.

13. De Leon-Casasola OA, Plancarte R, Patt RB, Lema MJ. Superior hypogastric plexus block using a single needle and computed tomography guidance. Reg Anesth 1993;18:63.

14. De Leon-Casasola OA, Plancarte R, Patt RB, Lema MJ. Superior hypogastric plexus block using a single needle and computed tomography guidance. Reg Anesth 1993;18:63.

15. Plancarte R, De Leon-Casasola OA, El-Helaly M, Allende S, Lema MJ. Neurolytic superior hypogastric plexus block for chronic pelvic pain associated with cancer. Reg Anesth 1997;22:562-8.

16. Gamal G, Helaly M, Labib Y. Superior hypogastric block: Transdiscal versus classic posterior approach in pelvic cancer pain. Clin J Pain 2006;22:544-7.

17. Plancarte R, Amescua C, Patt R. Presacral blockade of the ganglion of Walther [ganglion impar]. Anesthesiology 1990;73:A751.

18. Munir M, Zhang J, Ahmad M. A modified needle-inside needle technique for the ganglion impar block. Can J Anaesth 2004;51:915-7.

19. Nebab E, Florence I. An alternative needle geometry for interruption of the ganglion impar. Anesthesiology 1997;86:1213-4.

20. Toshniwal G, Dureja G, Prashanth S. Transsacrococcygeal approach to ganglion impar block for management of chronic perineal pain: A prospective observational study. Pain Physician 2007;10:661-6. 


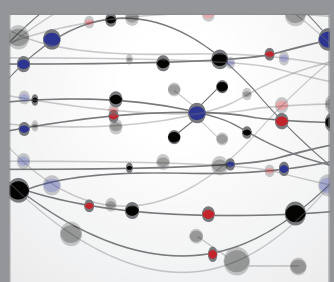

The Scientific World Journal
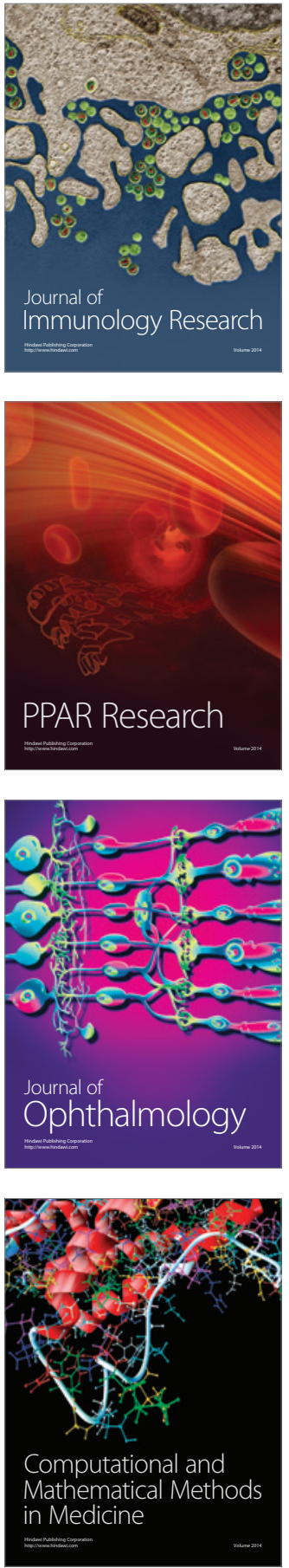

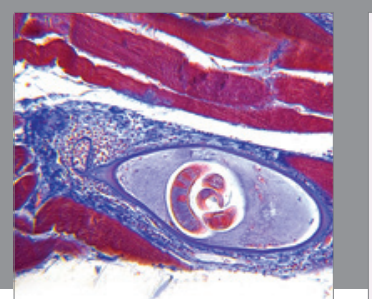

Gastroenterology Research and Practice

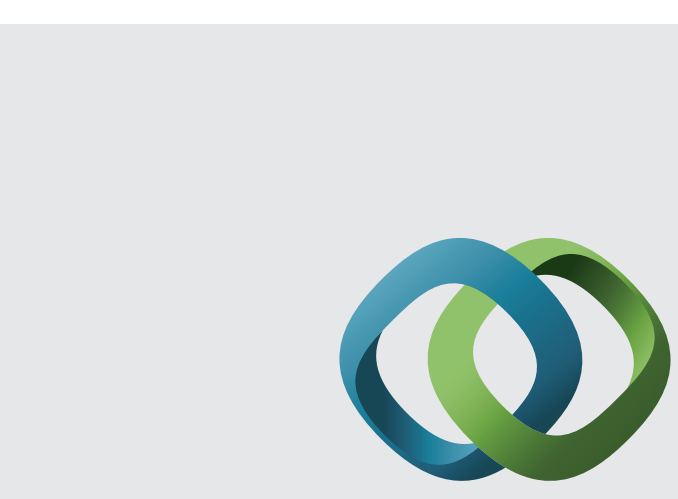

\section{Hindawi}

Submit your manuscripts at

http://www.hindawi.com
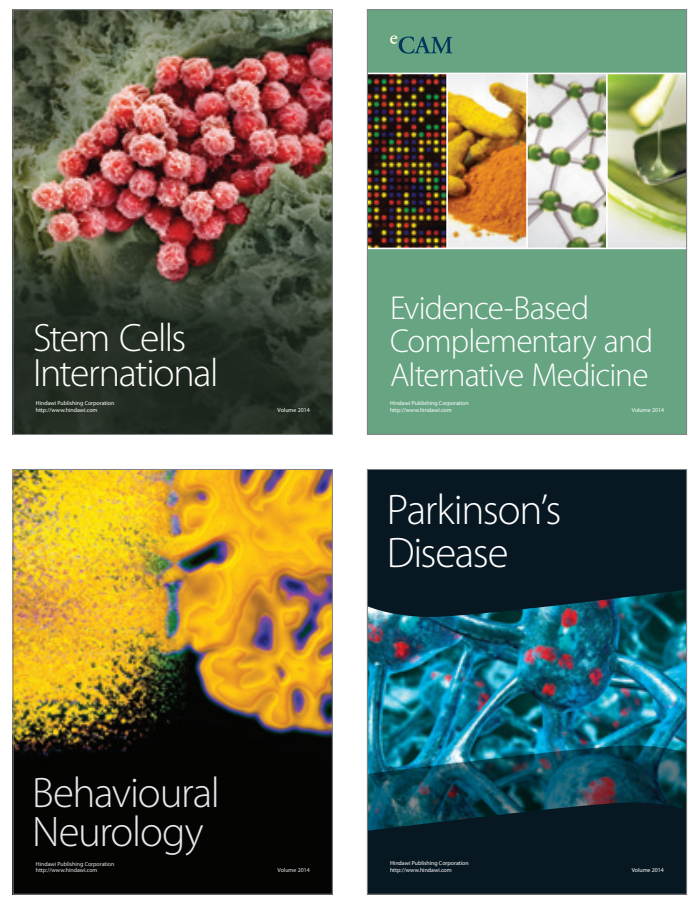
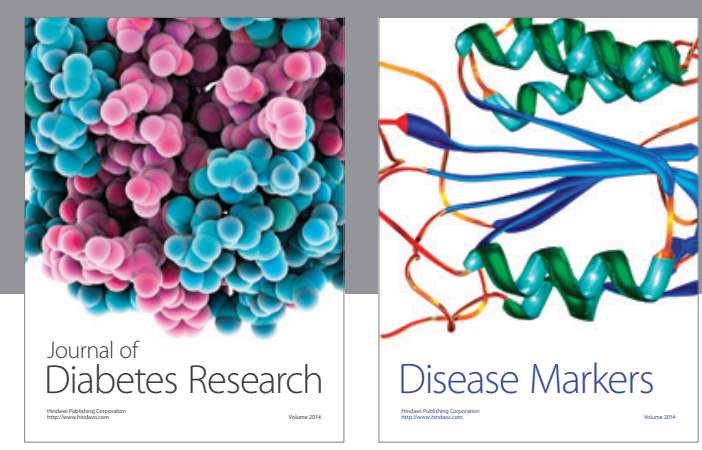

Disease Markers
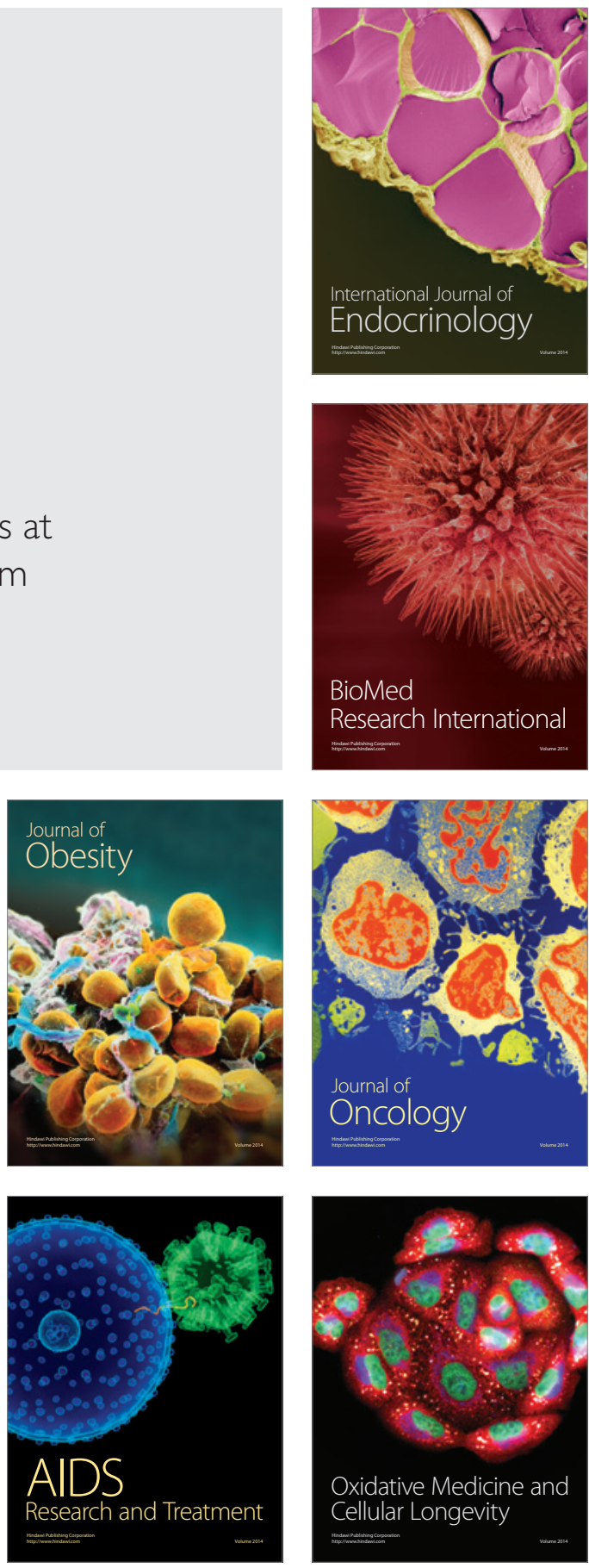